\title{
New methods in provenance studies based on heavy minerals: an example from Miocene sands in Jylland, Denmark
}

\author{
Christian Knudsen, Dirk Frei, Thomas Rasmussen, Erik S. Rasmussen and Roger McLimans
}

New techniques using Computer Controlled Scanning Electron Microscopy (CCSEM) and Laser Ablation - Inductively Coupled Plasma - Mass Spectroscopy (LA-ICP-MS) have recently been developed at the Geological Survey of Denmark and Greenland (GEUS) to determine source, compositional variation and sedimentary pathways of sandstones. These new time- and cost-efficient methods are highly applicable in petroleum and mineral exploration. This paper illustrates how the provenance and variability of Miocene titanium-rich sands in western and central Jylland have been investigated, but the methods are presently also used offshore the Faroe Islands and in East and West Greenland.

CCSEM and LA-ICP-MS utilise simple sample preparation methods, are relatively rapid and less expensive than conventional methods and yield more information.

\section{Heavy mineral (titanium) exploration techniques}

Exploration for economic concentrations of valuable heavy minerals, particularly Ti-bearing minerals, necessitates knowledge of their compositional variation and the sand transport processes into the sedimentary basin where they are found (Morton \& Hallsworth 1999; Morton et al. 2004). Conventional provenance studies employ methods such as Sensitive High Resolution Ion MicroProbe (SHRIMP) and Electron MicroProbe Analysis (EMPA) that require time-consuming and often tedious sample preparation, are thus expensive, and are therefore not suitable as a standard exploration technique. As part of a provenance study of ilmenite-rich sands occurring in the Miocene of western Denmark carried out at GEUS, it was the aim to develop a more cost-efficient standard analytical tool that could integrate bulk rock chemostratigraphic data, mineral compositional data and age information. This study describes the use of CCSEM and LA-ICP-MS as alternative techniques, capable of providing detailed information relevant to sand provenance more rapidly and less expensively than conventional methods.

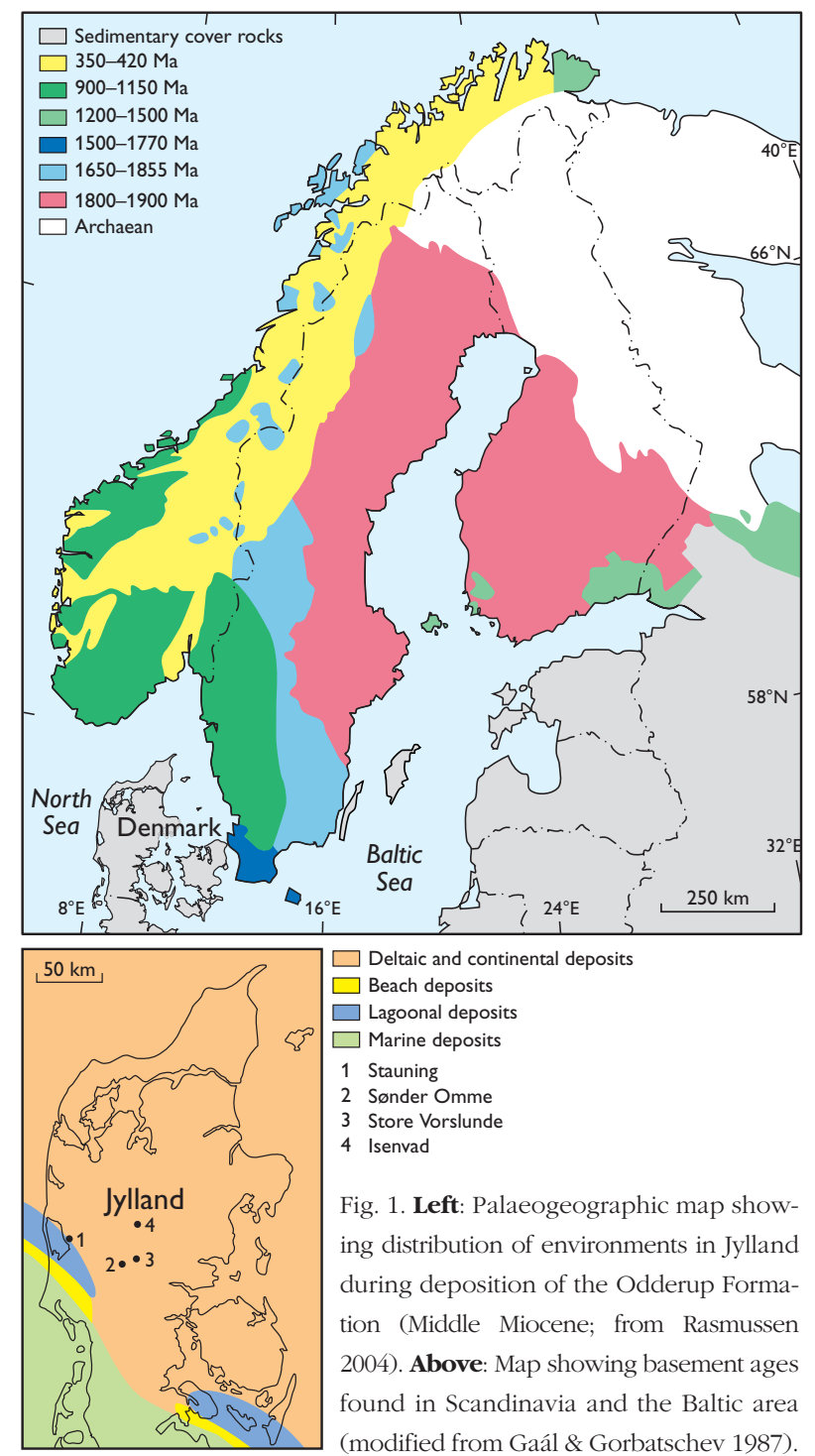

\section{General geological setting}

The coastline of the proto-North Sea had a NW-SE trend across central Jylland during the Miocene (Fig. 1). The coastal regions were sourced by large rivers draining the western part of the Scandinavian shield during the early Miocene. A distinct change to a more westerly transport direction occur- 


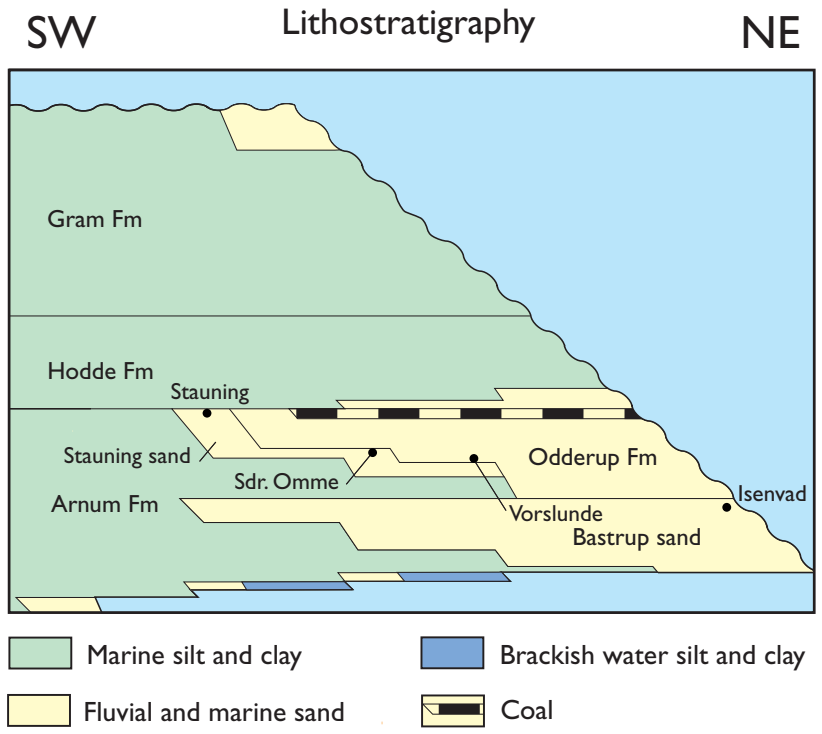

Fig. 2. Simplified Miocene lithostratigraphy of the study area with position of sample localities indicated (modified from Rasmussen et al. 2004)

red during the mid-Miocene (Rasmussen 2004). The climate was warm temperate to subtropic. Heavy mineral enrichment has been found in beach sands of what were barrier islands (Odderup Formation and Bastrup sand) and in offshore storm sand deposits (Stauning sand, Figs 1, 2; Knudsen 1998; Fisher 2003).

\section{Major and trace element geochemistry}

During exploration for heavy mineral accumulations, a large number of drill holes were completed in western and central Jylland. Ilmenite-bearing sand samples (bulk rock) from the drill holes were analysed by X-ray fluorescence (XRF). In the Vorslunde area, the analytical results show that the finegrained micaceous sand belonging to the Stauning sand (Rasmussen 2004) has a distinct geochemical signal compared to the overlying medium-grained quartz sand of the Odderup Formation (Fig. 3).

The Fe/Ti ratio (Fig. 3A) is higher in the Stauning sand compared to the Odderup Formation as iron is leached out of the ilmenite during alteration of the sediment (Weibel 2003). The higher Fe/Ti ratio in the Stauning sand indicates that it has suffered less leaching than the Odderup Formation.

The V/Ti ratio (Fig. 3B) is higher in the Stauning sand than the Odderup Formation, indicating a higher vanadium content in the ilmenite of the Stauning sand. As vanadium is less likely to be leached out of the ilmenite than iron, this may reflect a difference in the composition of ilmenite in the source areas for the sands in the two units.
The Y/Ti ratio (Fig. 3C) is higher in the Stauning sand than the Odderup Formation indicating that the Stauning sand has a different heavy mineral assemblage; presumably a higher content of primary monazite and xenotime which are the main carriers of yttrium. This may indicate a different ratio between monazite and xenotime in the source regions of the two units.

\section{Computer controlled scanning electron microscopy}

The CCSEM method, developed and applied in provenance analyses at GEUS (Frei et al. 2005), provides the following:

1. Modal abundances of the heavy minerals.

2. Major element composition of the individual grains.

3. Grain-size and grain-shape data for the grains.

4. Maturity of the Ti-minerals.

For CCSEM analysis, the bulk sample and 500 to 1500 grains of the heavy mineral fraction obtained by heavy liquid separation are embedded in epoxy such that no grains touch each other.
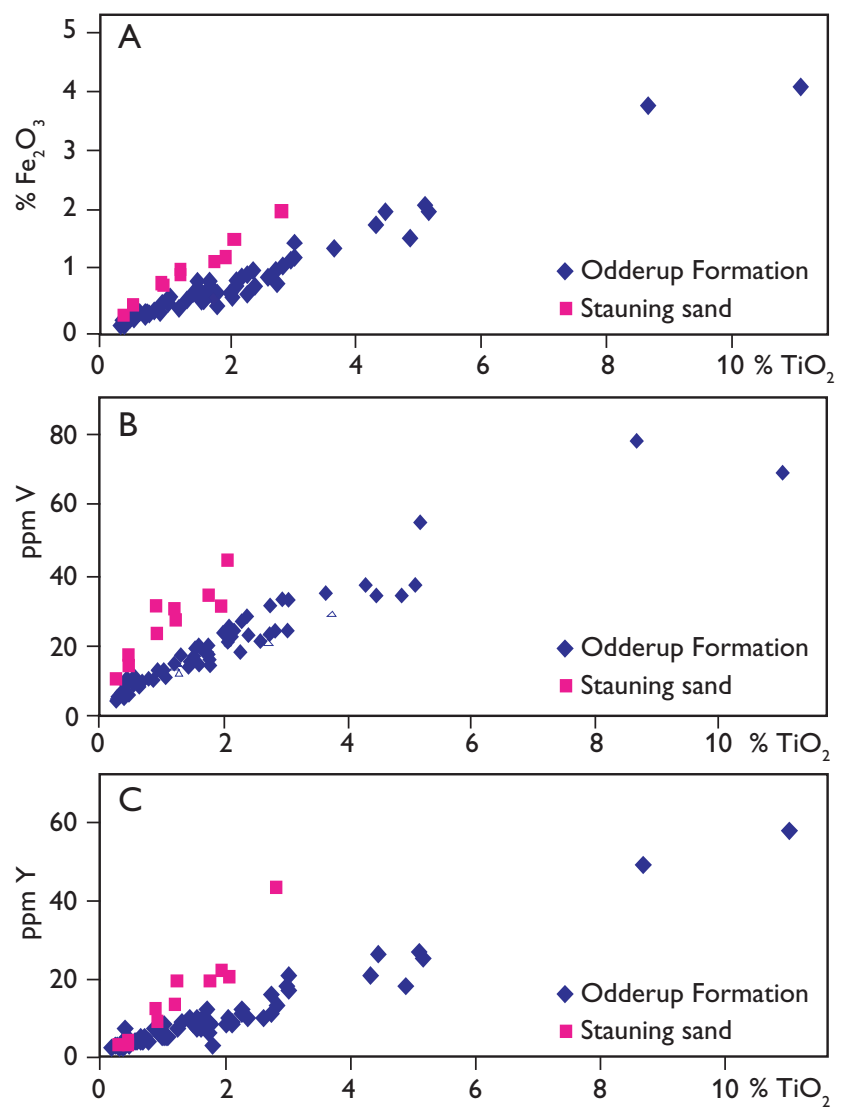

Fig. 3. XRF analyses of sand from the Vorslunde area. For location, see Fig. 1. 


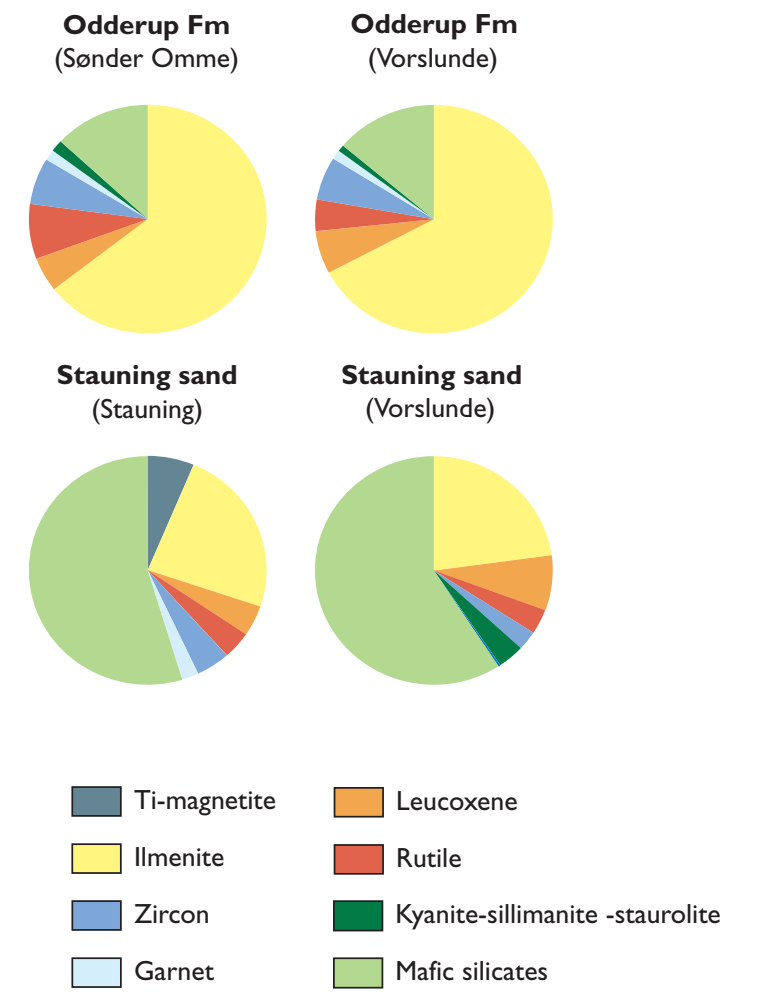

Fig. 4. Modal abundances in the heavy mineral fraction of Odderup Formation sand and Stauning sand determined by CCSEM. For location, see Fig. 1.

\section{Modal abundances of the heavy mineral suite}

The chemical composition of the grains is detected as well as such physical parameters as aspect ratio, circularity, perimeter, length and number of grains counted. This information is used to calculate the modal abundances and grain-size distributions of the detected minerals. In Fig. 4, the modal abundance of heavy minerals in the Odderup Formation is compared to the underlying Stauning sand. The Odderup Formation is dominated by stable heavy minerals such as ilmenite, rutile and zircon, whereas the Stauning sand contains a large proportion of mafic silicates vulnerable to dissolution during alteration (Weibel 2003), indicating a higher maturity of the Odderup Formation sands.

\section{Titanium content of the titanium minerals}

The $\mathrm{TiO}_{2}$-distribution in the Ti-mineral fraction (i.e. ilmenite, rutile and leucoxene) of a sediment is a very sensitive indicator of its maturity. The continuous alteration of primary ilmenite (with an average stoichiometric $\mathrm{TiO}_{2}$-content around $50 \mathrm{wt} \%$ ) to leucoxene by leaching of iron, leads to a significant increase in the $\mathrm{TiO}_{2}$-grade of the Ti-mineral fraction in a mature sediment (e.g. Weibel 2003). Since the
CCSEM analysis yields the average chemical compositions of all minerals present in a given sample, the $\mathrm{TiO}_{2}$-distribution of the Ti-mineral fraction can easily be calculated without the need for time-consuming mineral separation. The average $\mathrm{TiO}_{2}$-content of around $68 \mathrm{wt} \%$ observed in the Odderup Formation (Fig. 5) is indicative of a mature sediment. In contrast, the majority of the data for the Stauning sand scatters around the normal $\mathrm{TiO}_{2}$-content of $50 \mathrm{wt} \%$ (Fig. 5), characteristic of primary, unleached ilmenite, indicating a less mature sediment. This supports the interpretation of Fig. 3A mentioned above.
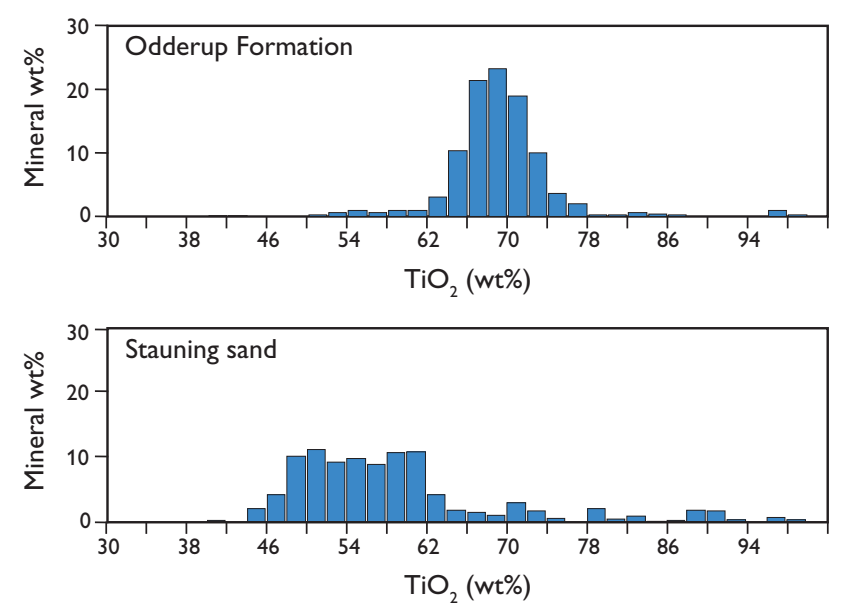

Fig. 5. Distribution of $\mathrm{TiO}_{2}$-content of the Ti-mineral fraction in the Odderup Formation and the Stauning sand at Vorslunde, determined by CCSEM. The higher $\mathrm{TiO}_{2}$-content in the quartz sand reflects its higher maturity. For location, see Fig. 1.

\section{Garnet composition}

The compositional variability of the detrital garnet fraction in sediments is also a very useful provenance indicator (e.g. Morton 1985; Morton \& Hallsworth 1994). Garnet compositions are normally determined by point-counting a representative number of grains using electron microprobe analysis. Using CCSEM, information on the chemical variability of the garnet fraction in a sample is acquired concomitantly with the titanium mineral data during routine operation, i.e. no further sample preparation or analytical steps are required.

\section{Laser Ablation - Inductively Coupled Plasma - Mass Spectrometry}

For LA-ICP-MS age determinations, zircons are separated from the bulk samples using conventional heavy liquid and magnetic separation methods. The final separation step is 

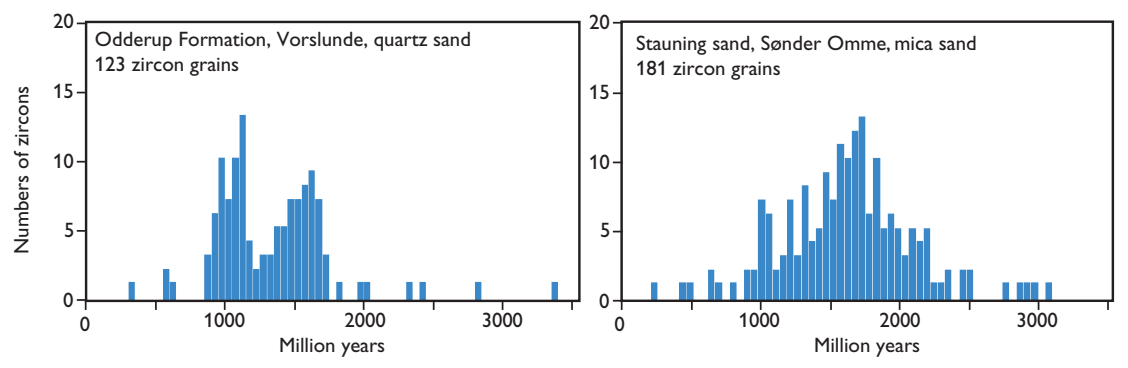

Fig. 6. Age distribution among detrital zircons from Miocene sands in Jylland. Note the bimodal distribution of zircon ages in the Odderup Formation and the Bastrup sand in contrast to the unimodal and generally older ages in the Stauning sand (see text for discussion).

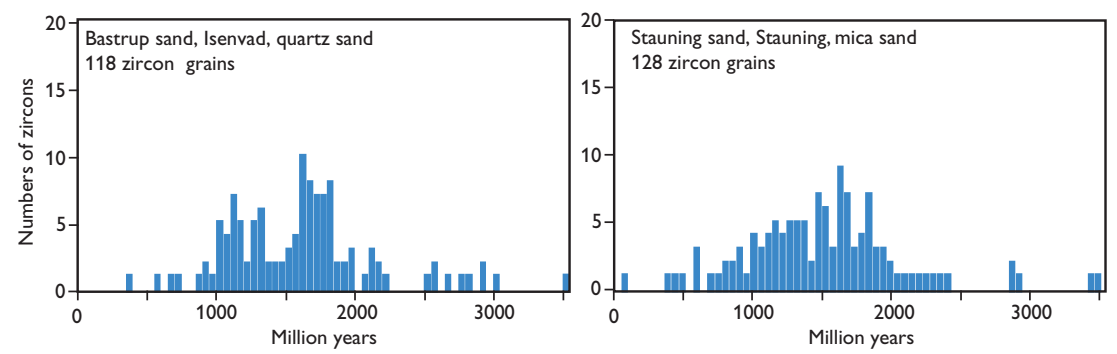

made by hand-picking individual zircon grains using an optical microscope. For analysis, the individual detrital zircon grains are mounted on adhesive tape. The LA-ICP-MS dating is based on measuring the ${ }^{207} \mathrm{~Pb}-{ }^{206} \mathrm{~Pb}$ ratios in the zircon, and the data are in good agreement with data from SHRIMP analyses (Frei et al. 2005).

The different provenance of the various Miocene sandy units is also reflected by their detrital zircon age distribution data (Fig. 6) . The Bastrup sand and the Odderup Formation are characterised by a bimodal distribution of the ages, with peaks around 1100 and $1600 \mathrm{Ma}$, whereas the Stauning sand has a broad distribution with a single peak around $1500 \mathrm{Ma}$ and a scattering of ages between $2500 \mathrm{Ma}$ and $3000 \mathrm{Ma}$. When compared to the map showing the distribution of ages in the Scandinavian shield and the Baltic area (Fig. 1), a north and north-easterly provenance for the Bastrup sand and the Odderup Formation is likely, whereas the Stauning sand probably has a more easterly source, where older rocks are more common. However, the Bastrup sand and the Odderup Formation are coarser grained, and were not deposited in the same environment. There is a possibility that the differences are due to Sveco-Norwegian zircons being larger and thus being less frequent in the fine-grained sediments of the Stauning sand.

\section{Acknowledgement}

The results presented here are a part of a study carried out with financial support from DuPont Titanium Technologies.

\section{References}

Fisher, T. 2003: Georadar investigations and sedimentology of Miocene heavy mineral deposits, central Jylland, 178 pp. Unpublished M.Sc. thesis, University of Copenhagen, Denmark.

Frei, D., Rasmussen, T., Knudsen, C., Larsen, M., Whitham, A. \& Morton, A. 2005: Linking the Faroese area and Greenland: new methods and techniques used in an innovative, integrated provenance study. Annales Societatis Scientiarum Færoensis Supplementum 43, 1-7.

Gaál, G. \& Gorbatschev, R. 1987: An outline of the Precambrian evolution of the Baltic Shield. Precambrian Research 35, 15-52.

Knudsen, C. 1998: Heavy mineral exploration in Miocene sediments, Jylland. Danmarks og Grønlands Geologiske Undersøgelse Rapport 1998/45, $44 \mathrm{pp}$.

Morton, A.C. 1985: A new approach to provenance studies: electron microprobe analysis of detrital garnets for Middle Jurassic sandstones of the northern North Sea. Sedimentology 32, 553-566.

Morton, A.C. \& Hallsworth, C.R. 1994: Identifying provenance-specific features of detrital heavy mineral assemblages in sandstones. Sedimentary Geology 90, 241-256.

Morton, A.C. \& Hallsworth, C.R. 1999: Processes controlling the composition of heavy mineral assemblages in sandstones. Sedimentary Geology 124, 3-29.

Morton, A.C., Hallsworth, C. \& Chalton, B. 2004: Garnet compositions in Scottish and Norwegian basement terrains: a framework for interpretation of North Sea sandstone provenance. Marine and Petroleum Geology 21, 393-410.

Rasmussen, E.S. 2004: Stratigraphy and depositional evolution of the uppermost Oligocene-Miocene succession in western Denmark. Bulletin of the Geological Society of Denmark 51, 89-109.

Rasmussen, E.S., Dybkjær, K. \& Piasecki, S. 2004: The Billund delta: a possible new giant aquifer in central Jutland. Geological Survey of Denmark and Greenland Bulletin 4, 21-24.

Weibel, R. 2003: Alteration of detrital Fe-Ti oxides in Miocene fluvial deposits, central Jutland, Denmark. Bulletin of the Geological Society of Denmark 50, 171-183.

\section{Authors' addresses}

C.K., D.F., T.R. \& E.S.R., Geological Survey of Denmark and Greenland, Øster Voldgade 10, DK-1350 Copenhagen K, Denmark. E-mail: ckn@geus.dk R.McL., DuPont Titanium Technologies, Experimental Station, E352/217, Route 141 and Henry Clay, Wilmington, DE 19808, USA. 